Examining the link between Humble Leadership and Innovative Behaviour ...

Dr. Sameh Abd-ElMaksoud Aboul-Dahab

\title{
Examining the link between Humble Leadership and Innovative Behaviour through Psychological Capital, Psychological Empowerment, and Work Engagement:The moderating role of Top Management Support
}

\section{Dr. Sameh Abd-EIMaksoud Aboul-Dahab}

Business Administration Department, Faculty of Commerce, Kafrelsheikh University, Egypt

\section{E-Mail: sameh.abdelmaksod@com.kfs.edu.eg}

\section{Abstract :}

The main purpose of our study was to examine the direct and indirect link between humble leadership and innovative behaviour. It also examined the role of top management support as a moderating role. We collected data from 391 employees in the hospitality context in Egypt. Structural equation modelling was used to analyse the data. The results indicated that there is a direct effect of humble leadership on employees innovative behaviour. Both psychological capital, work engagement, and psychological empowerment mediate the link between humble leadership and innovative behaviour. It also revealed that top management support moderates this relationship. This study offers meaningful implications for managers in the hospitality industry. 
Examining the link between Humble Leadership and Innovative Behaviour ...

Dr. Sameh Abd-ElMaksoud Aboul-Dahab

\section{Keywords;}

Humble leadership, Innovative behaviour, Work engagement, Top management support.

\section{Introduction}

In a worldwide commercial centre where issues are progressively mind boggling and flighty, it turns out to be more hard for pioneers at the top to sort everything out (Sethuraman and Suresh, 2014). The customary model, which depends entirely on the insight of pioneers, is as of now genuinely deficient in the dynamic and unsure hierarchical climate. Given this present, the present associations progressively depend on representatives taking activities in taking care of issues, in looking for approaches to change work circumstances, and in making developments to improve the association's viability. Seeing how to induce representative proactive conduct has significant hypothetical and functional importance and will turn out to be progressively basic (Dulewicz and Higgs, 2005). Exploration has shown that pioneers are a possibly significant logical factor in representative proactive conduct (Crant, 2000). Pioneers' help, support, and appreciation have been discovered to be related with expanded representative proactive conduct (Al Khajeh, 2018).

Examination on friendly data preparing hypothesis gives a hypothetical premise to seeing what humble administration means for supporter imagination. Social data handling hypothesis 
Examining the link between Humble Leadership and Innovative Behaviour ...

Dr. Sameh Abd-ElMaksoud Aboul-Dahab

recommends that people depend on data prompts to comprehend the workplace and control their practices (Saeed et al., 2014). Pioneers fill in as a key data source, given their higher status and direct inclusion and cooperations with supporters (Gandolfi and Stone, 2018). Along these lines, the social displaying of a modest pioneer in dyadic communications may shape a mentally protected climate, where may support their inventive practices. Mental wellbeing portrays the common view of the outcomes of facing relational challenges in their workplace (Edmondson, 1999), and the impression of safe environment is viewed as a significant precondition vital for devotee innovativeness (Van Engen and Willemsen, 2004).

Over a few decades, innovative behaviour has been the main focus of project management literature (Ika et al., 2012). Among the component of the exploration that has expanded our comprehension of the variables basically affecting venture achievement is authority style (Vinkenburg et al., 2011; Zopiatis and Constanti, 2010). However, a few parts of the administration styles impacting project achievement still can't seem to be investigated, as scientists recommend that researchers should center the job of all parts of initiative with project achievement, rather than simply centering a couple (Kuchinke,1999). Among the administration styles, humble authority has been characterized regarding three primary qualities: (1) willing to view oneself accurately,(2) an appreciation others' strengths 
Examining the link between Humble Leadership and Innovative Behaviour ...

Dr. Sameh Abd-ElMaksoud Aboul-Dahab

and(3) openness to novel thoughts and input (Hussain and Hassan, 2016). Despite the fact that researchers have accentuated that lowliness is required greatness for project chiefs (Briere et al., 2015), yet up to our knowledge, no researches conducted previously to empirically examine the positive impact of humble authority on innovative behaviour. Albeit, past research gives some proof about the part of humble initiative in project achievement. For example, humble initiative cultivates the versatile qualities inside the group they lead, which eventually upgrades project group execution (Angus-Leppan, Metcalf, and Benn, 2010) at the fruitful fulfilment of the task. Therefore, this research aims to examine that humble leadership has a positive impact on employees innovative behaviour through work engagement, psychological capital, and psychological empowerment. Our study also examines the moderating role of top management support on the study variables.

\section{Literature review}

\subsection{Humble leadership}

With an ever increasing number of researchers investigating the undertone of lowliness, modesty in initiative is continuously being perceived and profoundly applauded in an undeniably unique and dubious market climate. The agreement on humble administration is that unassuming pioneers are by and large willing to see themselves precisely, to acknowledge that there is 
Examining the link between Humble Leadership and Innovative Behaviour ...

Dr. Sameh Abd-ElMaksoud Aboul-Dahab

an option that could be more noteworthy than themselves, and to focus on the development and advancement (Huertas-Valdivia, Gallego-Burín, and Lloréns-Montes, 2019). In spite of the fact that quietude in scholarly exploration started in the West, it is a center fundamental of Chinese Confucian culture. Taking into account that the idea and construction of initiative is inserted in each culture and changes as indicated by culture, this paper embraces the meaning of humble authority created by Chen et al. (2017) in a Chinese social setting. The definition, from a conduct point of view, characterizes humble authority as congeniality, right mindfulness, an enthusiasm for others' qualities and commitments, and receptiveness to input. Albeit humble authority has been related with a few significant results, for example, CEOs' enabling conduct (Rahbi, Khalid, and Khan, 2017), representative work commitment, work execution and turnover (Owens et al., 2013), and group execution (Pashiardis and Brauckmann, 2011), the exact help is lacking. It is fundamental for more experimental examinations to profoundly explain the interaction and conditions how and when humble authority advances wanted results (Fiaz, Su, and Saqib, 2017), for instance, worker imaginative conduct at work. 
Examining the link between Humble Leadership and Innovative Behaviour ...

Dr. Sameh Abd-ElMaksoud Aboul-Dahab

\subsection{Employees innovative behaviour}

Humble leadership is a multidimensional develop that envelops four social sub dimensions: romanticized impact; rousing inspiration; scholarly incitement; and individualized thought (Cummings et al., 2018). Glorified impact (appeal) is shown when pioneers 'provide(s) vision and feeling of mission, imparts pride, gains regard and trust'. Uplifting inspiration alludes to authority practices that add non-scholarly, enthusiastic characteristics to the impact cycle, for example, showing an activity direction, trying to assemble representatives' certainty through verbal correspondences, and motivating faith in the reason (Bednall et al., 2018). Individualized thought includes offering help for devotees (Eid and Agag, 2020, for example, tutoring or training, checking execution and doling out fittingly testing undertakings. Scholarly incitement alludes to endeavors to persuade devotees to see and move toward difficulties recently. Groundbreaking initiative goes past value-based authority, which is centered around building up a trade relationship with devotees to accomplish indicated objectives for remunerations. While value-based authority is a significant reason for powerful initiative, it is lacking to rouse inventive conduct (Amankwaa, Gyensare, and Susomrith, 2019). In view of discoveries that undeniable degrees of groundbreaking administration are related with imaginative conduct, analysts have contended that significant degrees of groundbreaking authority rouse representatives to go past expected execution levels (for 
Examining the link between Humble Leadership and Innovative Behaviour ...

Dr. Sameh Abd-ElMaksoud Aboul-Dahab

example Orth and Volmer, 2017). Mumford et al. (2002) recommended that advancement requires an influential visionary pioneer, who will support a thought and is equipped for affecting others in the association to receive it. Likewise, Mutonyi, Slåtten, and Lien (2020) contended that moving inspiration ought to invigorate workers' natural inspiration on an innovative undertaking and increment imaginative self-viability. EscribáCarda et al (2017) contended that scholarly incitement urges representatives to think about elective points of view, devise novel thoughts, and examination with new methodologies. At long last, Chung and Kim (2017) proposed that individualized thought empowers pioneers to comprehend representatives' requirements, abilities and desires better, giving support and acknowledgment to innovativeness. A disregarded inquiry concerns whether ground breaking administration directly applies an impact on imaginative practices at high, medium and low levels, or whether the relationship is curvilinear to such an extent that it is more grounded at high and low levels and more vulnerable at moderate levels. Responding to this inquiry may go some route towards tending to irregularities in the writing that as of now keep down estimating and the degree for functional direction here (Farid, Hakimian, and Ismail, 2017; Su, Wang, and Chen, 2020). 
Examining the link between Humble Leadership and Innovative Behaviour ...

Dr. Sameh Abd-ElMaksoud Aboul-Dahab

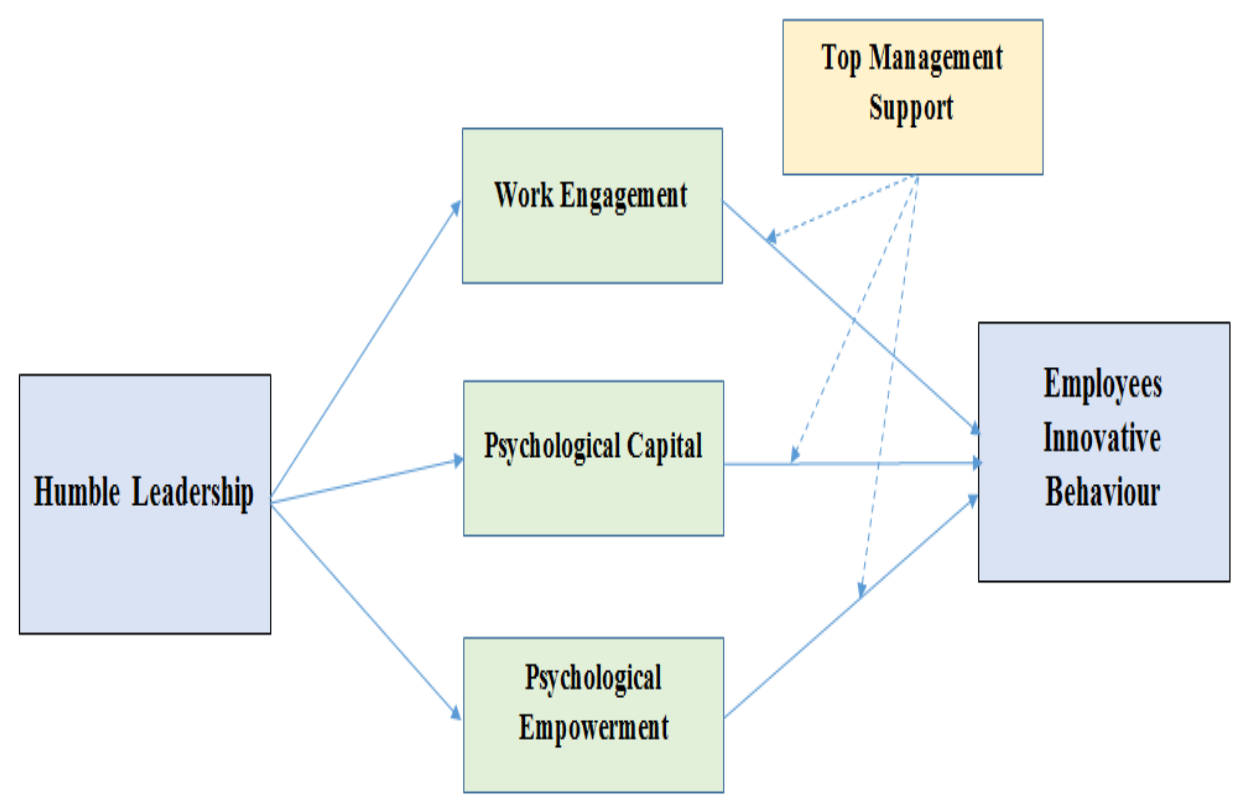

Fig.1. the Research Model

\subsection{Humble leadership and employees innovative behaviour}

Humble leadership is a behaviour based authority style and consists of three centre measurements (Montani et al., 2018; Sharma, 2017): (a) showed readiness to see the self precisely. This measurement depicts a pioneer will in general join an exact self-attention to individual qualities and limits. Also, pioneers and devotees would have a more palatable and straightforward interpersonal

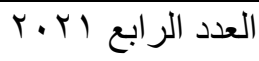


Examining the link between Humble Leadership and Innovative Behaviour ...

Dr. Sameh Abd-ElMaksoud Aboul-Dahab

cooperation through such an exposure of individual shortcoming. (b) enthusiasm for others' qualities and commitments. When all is said in done, humble pioneers are unselfish. They hold a good perspective on others, and respect others' qualities and commitments instead of feeling compromised by them. (c) openness to instruction. The third component of humble authority portrays a pioneer showing responsiveness to novel thoughts, criticism and gaining from others. With openness to instruction, humble leaders are openminded. Humble authority has been related with representative attitudes and practices in past investigations (Baskaran and Rajarathinam, 2017). Here, we contend that unassuming initiative could advance creative conduct among medical attendants. In the first place, by displaying a target perspective on limits and shortcoming, humble pioneers will in general think about botches during the time spent advancement as typical (Gross and Cabanda, 2017; Will, Kfairy, and Mellor, 2017), which completely could develop more imaginative practices among medical caretakers. Second, by valuing supporters' qualities and contributions, humble pioneers spur and move medical caretakers to raise ground-breaking thoughts, ideas and arrangements to improve nature of care (Bos-Nehles, Renkema, and Janssen, 2017; Ghosh et al., 2019). At long last, by showing receptiveness to original thoughts and input, humble pioneers elevate medical attendants to produce and actualize new cycle and techniques by and by Abukhait, Bani-Melhem, and Mohd Shamsudin (2020). 
Examining the link between Humble Leadership and Innovative Behaviour ...

Dr. Sameh Abd-ElMaksoud Aboul-Dahab

Figure.1. demonstrates the study variables. Consequently, in view of these contentions, our first theory is:

Hypothesis 1: Humble leadership is has a significant influence on innovative behaviour.

\subsection{The mediating role of work engagement, psychological capital, and psychological empowerment}

Work engagement alludes to a 'positive, satisfying, work related perspective that is portrayed by energy, devotion, and assimilation' (Bos-Nehles, Renkema, and Janssen, 2017). A few examinations have additionally archived that drawn in attendants will in general show less turnover goals, report higher work effectiveness and give patient centred care (Montani et al., 2018). Along these lines, it is critical to examine the indicators and results of medical attendants' work commitment. Commitment in work suggests that people put extraordinary individual venture of physical, passionate and intellectual energy into their work (Bakker and Albrecht, 2018 Engelbrecht, Heine, and Mahembe, 2017). Eminently, to produce and actualize something new in the organisations, people more likely than not contributed enormous and significant individual assets and endeavours, which additionally implies they must be occupied with work (Tsaur, Hsu, and Lin, 2019). Since imaginative conduct includes the age and usage of original thoughts, interaction and strategies, it requires singular representatives to be focused on their work and 
Examining the link between Humble Leadership and Innovative Behaviour ...

Dr. Sameh Abd-ElMaksoud Aboul-Dahab

be joyfully caught up in it (assimilation), have significant levels mental flexibility and diligence to manage troubles while working (energy), and have the sensation of eagerness, pride and importance in work (devotion) (Gawke, Gorgievski, and Bakker, 2017). Exactly, a new report has announced a positive connection between work commitment and inventive conduct among attendants (Gupta, Shaheen, and Reddy, 2017). Furthermore, humble pioneers will in general perceive singular employees' commitments, which could advance their feeling of significant worth and accordingly lead to more elevated levels of work commitment. In addition, it's grounded that work commitment is a significant intervening variable (Mäkikangas, 2018). We hence expect that work commitment would play an intervening job in the relationship between humble initiative and attendants' inventive conduct. Working with an unassuming pioneer, medical caretakers are bound to put individual energy and assets in work stuffs (work commitment), and thus invigorate their inspiration and readiness to make and attempt ground-breaking thoughts and novel techniques in medical services practice. Taken together, we suggest that:

Hypothesis 2: Work engagement mediates the link between humble leadership and employees innovative behaviour.

Psychological capital (PsyCap) is characterized as one's certain mental condition of improvement, including: self-viability, good 
Examining the link between Humble Leadership and Innovative Behaviour ...

Dr. Sameh Abd-ElMaksoud Aboul-Dahab

faith, expectation, and versatility (Gutermann et al., 2017). PsyCap has been discovered to be flexible, open to advancement, and can be improved by pioneer practices. In this examination, we investigate the positive part of humble pioneer practices in creating supporter PsyCap. As referenced before, humble pioneers feature the common advancement al relationship with supporters. Despite the fact that these pioneers are quick to their self-awareness, they additionally trust that their displaying would spread infectiously to supporters (Anglin et al., 2018) and invigorate them to together take part being developed exercises loaded up with challenges. Thus, these followers are likely to have a more adaptive attitude toward challenges, namely, showing high versatility, since they might be sincerely familiar with handle these difficulties (Mao et al., 2020). Furthermore, by showing their own cutoff points, slip-ups and freshness, they urge devotees to reveal themselves (Luthans, Luthans, and Chaffin, 2019), "express their uncertainties and doubts and feel their way forward by experimenting through" (Gupta and Shaheen, 2017). Moreover, they also remind followers that errors and failure are the costs for learning, and assist them with learning the exercises and adjust he wrong courses (Gupta, Shaheen, and Reddy, 2017). These pioneer practices above are probably going to help improve adherents' objective coordinated assurance, extend their collection of potential answers for given errands and issues (hope).When humble pioneers spot light and appreciate supporter's qualities and commitments, even treat themselves as understudies of 
Examining the link between Humble Leadership and Innovative Behaviour ...

Dr. Sameh Abd-ElMaksoud Aboul-Dahab

their devotees' qualities (Kang and Busser, 2018), they may build adherents' self-appreciations adequacy and self-esteem, in this way prompting their positive examination of one's current and future conditions and showing an idealistic view about their future (Gooty et al., 2009). Taken together, we contend that modest pioneer practices apply a positive effect on devotee PsyCap. In help for our contention, chief lowliness is discovered to be identified with group PsyCap (Xu, Liu, and Chung, 2017). High-PsyCap workers proactively and reliably improve their PsyCap to perform better later on (Carmona-Halty et al., 2019). PsyCap's improvement centered nature encourages high-PsyCap adherents to take part in mind boggling and testing exercises (for example innovativeness) since experience collected by defeating deterrents and getting achievement causes them increment their PsyCap (Avey 2014). Past research has likewise recommended that PsyCap is decidedly identified with innovativeness (for example $\mathrm{Xu}$, Liu, and Chung, 2017). An essential illustrative instrument for the impact of PsyCap on supporter inventiveness is that those with high expectation will in general view difficulties as promising circumstances for gradual improvement or even extreme change (Agarwal and Farndale, 2017). Profoundly adequate supporters hold a solid confidence in their capacity to be fruitful regardless of troubles, they along these lines are bound to embrace those dangerous and testing exercises (for example innovativeness) and to put forth more attempt in their imaginative undertakings (Bandura, 1997) by activating their 
Examining the link between Humble Leadership and Innovative Behaviour ...

Dr. Sameh Abd-ElMaksoud Aboul-Dahab

inspiration, psychological assets and game-plans, and investing more energy in inventive intellectual cycles in distinguishing issue and producing new arrangements (Bockorny, and Youssef-Morgan, 2019). Besides, confident people pattern to notice issues from various points, and to zero in on innovative methodologies for tackling issues (Zhou and George, 2003). They are probably going to produce innovative thoughts, since they show solid objective guided assurance and the capacity to determine elective pathways to accomplish their objectives (Ortega-Maldonado, and Salanova, 2018). Even with mishaps and disappointment that may emerge from the imaginative interaction, idealistic people will in general credit these to transitory, not to individual in sufficiency (Bouzari and Karatepe, 2017), and flexibility empowers them to skip back and support undeniable degrees of exertion all the while, which builds the chance of accomplishing inventive results. Generally speaking, supporters with high PsyCap are bound to take part in imaginative exercises, put in more exertion, and produce more inventive thought.

Hypothesis 3: Psychological capital mediates the link between humble leadership and employees innovative behaviour.

Hypothesis 4: Psychological empowerment mediates the link between humble leadership and employees innovative behaviour. 
Examining the link between Humble Leadership and Innovative Behaviour ...

Dr. Sameh Abd-ElMaksoud Aboul-Dahab

\subsection{The moderating role of top management support}

Top administration alludes to the key leaders of the association including the CEO, head working official, CFO, specialty unit heads and VP (Ali et al., 2020). Top administration of any association is the basic partner of a project because of its role in designing the project and providing support to a project manager to guarantee its effective usage (Mughal, Bahaudin, and Salleh, 2019).Young and Poon (2013) attested that top administration uphold is the achievement factor for projects. Drawing on the fundamentals of the protection of asset hypothesis (Jungbauer et al., 2018), top administration backing might be arranged as asset parade paths in pioneers' work space that encourages the pioneers to use and develop the hierarchical assets productively. By satisfying the requirements for regard, objectives, choosing financial plans, giving human, material and specialized assets (Birasnav, and Bienstock, 2019), top administration backing may build pioneers' solace inside the association (Santos-Vijande et al., 2018). Top administration impacts a venture severally, like the arrangement of task supervisors, making a steady culture, portion of undertaking assets, vital arranging and executing the venture techniques (Mokhber, Khairuzzaman, and Vakilbashi, 2018). Top administration collaborates with the undertaking supervisor and colleagues to examine various issues identified with a venture (Chen and Popovich, 2003). Plus, the top administration uphold has a critical job in group building (Van

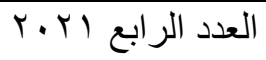


Examining the link between Humble Leadership and Innovative Behaviour ...

Dr. Sameh Abd-ElMaksoud Aboul-Dahab

Wart, et al., 2017).Top the executives exercises like sharing the association's vision, conveying arrangements and group building are viewed as firmly identified with project chief (Boonstra, 2013). In this way, we recommend that the modesty of a pioneer isn't sufficient to construct a group or effectively achieve a venture except if/she is upheld by the top administration of an association. Top administration appoints the power to project chiefs and worth their inputs, which makes the synergetic impacts in the workplace (Teoman, and Ulengin, 2018). Such community working practices improve the exhibition of the modest undertaking chief and colleagues (Owens and Hekman, 2016), which is a fundamental prerequisite for achieving a task. This proposes to reason that modest pioneers will just exercise the authority of appointing capacity to other people (center attributes of humble initiative) in the event that he/she has sufficient force assigned to him/her by the top administration of an association. Additionally, asking execution related criticism from the subordinates is another fundamental center attribute of humble initiative, which has been to be huge for group building and undertaking achievement. A modest pioneer must have the option to execute this quality if the way of life of the entire association is amicable, less administrative and helpful. This is principally the top administration of an association that generally plans the authoritative culture. This is steady with the past investigations that the obstructions eliminated by senior 
Examining the link between Humble Leadership and Innovative Behaviour ...

Dr. Sameh Abd-ElMaksoud Aboul-Dahab

administration to make project the board more compelling and upgrade the speed of venture conveyance (Mölders, et al., 2018). Top the executives is liable for assisting with making an animating and supporting the quick learning climate (Katsaros, Tsirikas, and Kosta, 2020). The impression of a protected environment energizes the task director, as unassuming pioneer who confesses the impediments, mix-ups and shows show capacity toward vulnerability (Muhammed, and Zaim, 2020), permits supporters have a sense of security to voice and communicate groundbreaking thoughts on an experimentation approach (Yang et al., 2019). Such consolation was centered around improving the proficiency of the colleagues with creative abilities and discovering openings for development and giving an inventive answer for difficulties confronting the work environment by permitting the association to achievement in the serious business environment (Jang, Zheng, and Bosselman, 2017; Saha et al., 2020). Remaining with our contentions, senior administration uphold has been found decidedly to impact the venture administrator and group, any snags related with advancement cycle will be all the more effectively survive, on the grounds that any deferrals because of interior causes will be quickly addressed and take project toward fruitful achievement.

Hypothesis 5: Top management moderate the link between the study variables. 
Examining the link between Humble Leadership and Innovative Behaviour ...

Dr. Sameh Abd-ElMaksoud Aboul-Dahab

\section{Methodology}

\subsection{Sample and data collection}

The fundamental study was done in Egypt, from February to March in 2019. The lodgings in Egypt are viewed as serving clients well and furthermore inventive, and workers of these inns come from different regions of Egypt, accordingly looking over inn representatives in Egypt may give suggestions to different regions of Arab nations. The scientists reached the administrators of Front Office (FO) and additionally Food and Beverage (F\&B) divisions in $\mathrm{OK}$ and five-star inns, which are viewed as more imaginative than lower-star lodgings (CTHA, 2014). Directors from seven lodgings consented to help this investigation and orchestrated the information assortment. Accommodation inspecting was utilized to choose representatives who were accessible for the review, with an arrangement to enrol half of the respondents from FO and half from F\&B divisions. Surveys were appropriated to representatives vis-à-vis. The analysts are unacquainted with all the respondents. During the study cycle, the analysts were absent while respondents finished the polls (we circulated the surveys, allowed for workers to round out the surveys, and gathered the surveys sometime in the not too distant future) to evade social attractive quality issues. Respondents were approached to restore the polls to the assigned assistance counter in their lodgings. 
Examining the link between Humble Leadership and Innovative Behaviour ...

Dr. Sameh Abd-ElMaksoud Aboul-Dahab

Inside and out 400 surveys were disseminated. Of the 400 polls gathered, 9 were disposed of on the grounds that there are excesses of missing qualities. Accordingly, 391 polls were held, Tests of information ordinariness were directed for all factors and results showed that all factors were around typically conveyed. Elucidating measurements were broke down for all review things with IBM SPSS Statistics 20.0. AMOS form 20.0 was utilized to direct corroborative factor investigation (CFA) for the estimations and underlying condition displaying (SEM) for the theories testing (Hair et al., 2009).

\subsection{Measurements}

The devices for central develops were received from past writing. All factors in examinations estimated on a five-point Likert scale going from emphatically deviate (1) to unequivocally disagree(5). Humble initiative was estimated with the nine thing scale created by Owens et al. (2013), with an alpha unwavering quality of 0.92 . Top administration uphold was estimated by utilizing the six-thing scale created by Wang, Liu, and Zhu (2018), with an alpha dependability of 0.89. Psy Cap was measured using a 24- item scale developed by Chen et al. (2019), including four measurements: self-adequacy, expectation, good faith, and versatility. Model things are "I feel certain defining objectives in my work territory" (self-viability), "There are loads of ways around any issue" (trust), "When things are questionable 
Examining the link between Humble Leadership and Innovative Behaviour ...

Dr. Sameh Abd-ElMaksoud Aboul-Dahab

for me at work, I as a rule anticipate the best" (good faith) and "When I have a mishap at work, I experience difficulty recuperating from it, proceeding onward" (versatility). Work engagement was estimated utilizing the nine item variant of the Utrecht Work Engagement Scale (UWES) (Schaufeli et al., 2019). It comprises of three components of work commitment including power, ingestion and devotion. Model things are 'At my work, I feel overflowing with energy' and 'When I am working, I fail to remember all the other things around me', which must be replied on a 7 point scale from 1 ('never') to 7 ('consistently'). The three measurements including Vigor, Absorption and Dedication were utilized as the three estimated pointers for work commitment. Creative conduct was surveyed utilizing $\mathrm{Ng}$ and Lucianetti (2016) nine item rendition of individual inventive conduct scale. It comprises of three elements of creative conduct including thought age (IG), thought advancement (IP) and thought acknowledgment (IR). Model things are 'I make novel thoughts for troublesome issues' and 'I change creative thoughts into helpful applications'. Members appraised this measure dependent on the 7 point scale from 1 ('unequivocally concur') to 7 ('emphatically oppose this idea'). 
Examining the link between Humble Leadership and Innovative Behaviour ...

Dr. Sameh Abd-ElMaksoud Aboul-Dahab

\section{Data Analysis and Results}

\subsection{Measurement model}

CFA was done to survey discriminant legitimacy of the builds. The results indicated that the Cronbach's qualities addressing the composite dependability of the multi-thing scales all surpass 0.7 , the suggested cut-off point (Tavakol and Dennick, 2011), showing an adequate degree of unwavering quality for each develop. Furthermore, all normal difference separated (AVE) of the develops are higher than 0.5, proposing high focalized legitimacy (Fornell and Larcker, 1981). Discriminant legitimacy is additionally affirmed by the way that AVE of each develop is higher than its squared relationship coefficients for between builds (Fornell and Larcker, 1981). For instance, the most elevated squared connection coefficient of representative imaginative conduct is $0.7210(=0.8540)$, lower than AVE esteem (0.64). Additionally, CFA results showed that the factor loadings for pointers are critical, with $\mathrm{p}<0.01$. In this way, the unwavering quality and legitimacy of the develops were worthy.

\subsection{Structural model assessment}

The SEM results of direct pathways for the hypothesized model were assessed. About the main influence, the results indicated a significant link between humble leadership and employees innovative behaviours $(\beta=0.569, \mathrm{p}<0.001)$, supporting H1. To look at the circuitous impact in $\mathrm{H} 2 \mathrm{c}$ all the more intently, we 
Examining the link between Humble Leadership and Innovative Behaviour ...

Dr. Sameh Abd-ElMaksoud Aboul-Dahab

followed Preacher et al's. (2007) ideas and directed the bootstrap examination. As indicated by Wang et al. (2017), the basic evaluations of backhanded impact ordinarily don't follow the typical idea and may bring about predisposition, and the bootstrap approach yields the most precise certainty spans for aberrant impact assessment.

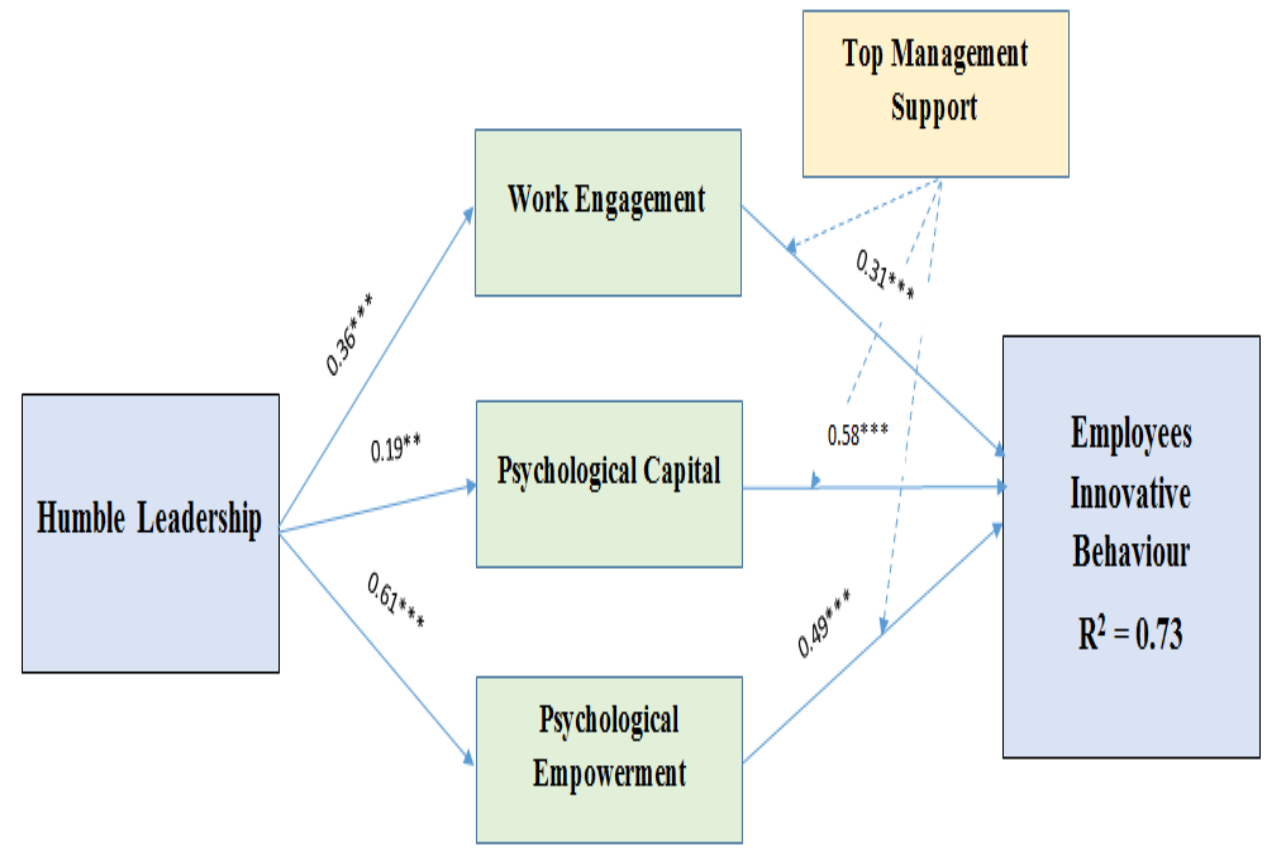

Fig.2. Study Results 
Examining the link between Humble Leadership and Innovative Behaviour ...

Dr. Sameh Abd-ElMaksoud Aboul-Dahab

Bootstrapping tests are persuasive in light of the fact that they distinguish when the examining conveyance of the intervened impact is slanted away from 0 (Shrout and Bolger, 2002). We determined $95 \%$ predisposition revised bootstrapped certainty spans (CIs) utilizing 5,000 information tests. The top and lower bound outcomes prohibit 0 for group building, which proposes that they are critical by ordinary guidelines. The bootstrap results show an emphatically huge intervening impact of work engagement between humble leadership and green behaviour $(\beta=0.392$, SE 5 $0.01, \mathrm{p}<0.05,95 \%$ CI $[0.01,0.06])$. Furthermore, psychological capital and empowerment were also supported. This results support $\mathrm{H} 2$, H3, and H4. To test H5, we utilized the PROCESS approach and led what is known as directed intercession or restrictive interaction investigation (Preacher and Hayes, 2008). A directed intercession model is portrayed by the concurrent presence of an arbitrator (for this situation, top administration uphold), which influences the strength of relationship between two different factors. The results supported $\mathrm{H} 5$.

\section{Discussion and conclusion}

In this investigation, we experimentally tried a model to analyze the job of humble authority in project achievement. A positive relationship between humble initiative and venture achievement was found. A task director, through his/her lowliness, may support and inspire colleagues toward the integrative conviction of venture 
Examining the link between Humble Leadership and Innovative Behaviour ...

Dr. Sameh Abd-ElMaksoud Aboul-Dahab

achievement portrayed by profitability, adequacy and satisfaction of partners. The consequences of this investigation propose that lowliness ought to be a fundamental nature of the undertaking supervisor to guarantee the effective execution of the task. Accordingly, this investigation upholds earlier examinations (Hughes et al., 2018). Additionally, this finding has tended to the hole called attention to by past researchers that the writing on project the board is inadequate to feature the part of undertaking supervisors' administration styles in project achievement (Bednall et al., 2018). The consequences of the examination have likewise settled a positive relationship between group building and task achievement. Our exploration shows that the current four components engaged with group building, in particular, project objective setting, job explanation, relational connections and critical thinking, could deliver a submitted and profoundly energetic undertaking group (Shuffler et al., 2018). This discovering underpins the past guarantee that through a productive group building cycle, associations and undertaking supervisors are bound to bring issues to light among colleagues about the venture targets, jobs and duties, relational collaboration and critical thinking abilities, which eventually impact a task success (Agag et al.,2016). Moreover, it was found that the team-building partially mediates the impact of humble authority on project achievement. This implies that unassuming initiative part of the way relies upon a fruitful group building measure while making project progress. This 
Examining the link between Humble Leadership and Innovative Behaviour ...

Dr. Sameh Abd-ElMaksoud Aboul-Dahab

examination likewise affirmed the directing impact of top administration uphold on the connection between humble authority and undertaking achievement. This discovering upholds the past research that senior administration moderating affects the connection between the task supervisor and venture execution (Kanwal et al., 2017). This outcome additionally shows the modest venture supervisor is putting the top administration uphold on the most noteworthy position for project achievement. The task chief should have the option to find support from the senior administration to finish the venture effectively. Examining top administration uphold emphatically moderate, the connection between humble authority and group building. Also, the investigation follows an earlier call for examination to investigate the directing part of top administration uphold between the venture supervisors and group building (Amankwaa, Gyensare, and Susomrith, 2019). Humble administration can be set up by steady top administration, where colleagues feel their info is esteemed and appreciated. Strong senior administration supports the inspiration to take part and give toward accomplishing shared objectives and regular reason. At the point when colleagues feel acknowledged and upheld inside their group and group pioneer, they might be more able to part concern, participate and submit toward the group's aggregate objectives.

These discoveries may have a few applied ramifications. To begin with, our outcomes highlight the significance of an unassuming 
Examining the link between Humble Leadership and Innovative Behaviour ...

Dr. Sameh Abd-ElMaksoud Aboul-Dahab

pioneer for project achievement. Modesty is a dearest quality that can be learned and created. Undertaking directors ought to be prepared with humble initiative styles, specifically through activity learning (Wang et al., 2018), which could be an approach to build the greatness of venture based associations. Lowliness is a relational and relationship or leased quality that can creates hared cooperation among representatives through formal and casual ways. The second aftereffects of our examination show that group constructing fundamentally intercedes the connection between humble administration and undertaking achievement. A pioneer's mindful job fabricates the expert group to deal with their work jobs, obligations, insight and exercises that are essential to perform well and accomplish set goals of the task. One ramifications acmes the adequacy of conventional group building systems, including formal and casual gathering level inclusions pointed toward improving social relations and explaining parts, just as tending to undertakings and relational issues that influence group working. This infers that there is a decent likelihood that ventures will succeed when the group building components are utilized effectively. The current exploration portrayed that this sort of execution by an organization cultivates an environment where team members feel competent, which results in group profitability (Shuffler et al., 2018). Third, our discoveries propose that help from top administration as far as giving assets, primary game plans, correspondence, mastery and forces is viable practices to upgrade the probability of undertaking 
Examining the link between Humble Leadership and Innovative Behaviour ...

Dr. Sameh Abd-ElMaksoud Aboul-Dahab

achievement and group building. The outcomes will assist the specialists to lead the tasks with more energy where senior administration could ensure the accessibility of fundamental help to the venture administrators. Senior administration touches off intelligence and critical thinking methods through the learning climate (Orth, and Volmer, 2017). Particularly when project usage time is short, humble venture chiefs and colleagues to deal with this component of learning can trigger the execution time. The writing shows that such help of top administration spurs project directors and undertaking groups to apply greatest endeavours and keep elite that at last prompts accomplishing project targets (Tsai, 2018).

\section{Limitations and future research}

The outcomes are restricted by our examination's cross sectional plan and by the utilization of a solitary strategy for information assortment. The way that information gathered from data innovation projects just cut off their generalizability, future investigations ought to likewise consider different sorts of venture based associations when examining the effect of humble administration. We didn't look at the part of authoritative culture as a directing variable. In any case, we accept that social variety can influence project achievement and group building, and future examinations ought to think about this viewpoint too. Another conceivable region of examination can be to consider the hidden system between humble authority and undertaking achievement, 
Examining the link between Humble Leadership and Innovative Behaviour ...

Dr. Sameh Abd-ElMaksoud Aboul-Dahab

as arbiters. Our examination has a few impediments in future exploration that should be settled. In the first place, our exploration considered the association between the essential builds instead of the expectations. Future exploration can utilize test configuration to decide the circumstances and logical results of such affiliations. Second, however the CFA recommended four unmistakable builds, because of the cross-sectional nature of the investigation, conceivable normal strategy fluctuation can't be overlooked. Be that as it may, we attempted to handle this issue somewhat by applying Harman'sone-factortest (Podsakoff et al., 2003). The outcomes introduced that the single factor represented just $22.9 \%$ of the change clarified not exactly the edge level of half (Khan, 2019), demonstrating that normal strategy premise not an extreme issue. Future scientists, notwithstanding, may gather information from various sources or over various occasions (cross-sectional) to eliminate potential predispositions related with cross-sectional information. The third impediment is the generalizability of the examination. To gather information, we zeroed in on one nation (Egypt) and one area (inns). Future examinations in different businesses and social settings may reproduce a similar report. All the more decisively, in light of the fact that modest administration is a relationship arranged authority style, near exploration ought to be completed among high and low relationship-situated societies to decide if the effect 
Examining the link between Humble Leadership and Innovative Behaviour ...

Dr. Sameh Abd-ElMaksoud Aboul-Dahab

of humble initiative on project achievement contrasts from one culture to another.

\section{References :}

Abukhait, R., Bani-Melhem, S. and Mohd Shamsudin, F., 2020. Do employee resilience, focus on opportunity, and work-related curiosity predict innovative work behaviour? the mediating role of career adaptability. International Journal of Innovation Management, 24(07), p.2050070.

Agarwal, P. and Farndale, E., 2017. High-performance work systems and creativity implementation: the role of psychological capital and psychological safety. Human Resource Management Journal,27(3), pp.440-458.

Al Khajeh, E.H., 2018. Impact of leadership styles on organizational performance. Journal of Human Resources Management Research, 2018, pp.1-10.

Ali, M., Li, Z., Khan, S., Shah, S.J. and Ullah, R., 2020. Linking humble leadership and project success: the moderating role of top management support with mediation of team-building. International Journal of Managing Projects in Business.

Amankwaa, A., Gyensare, M.A. and Susomrith, P., 2019. Transformational leadership with innovative behaviour. Leadership \& Organization Development Journal.

Amankwaa, A., Gyensare, M.A. and Susomrith, P., 2019. Transformational leadership with innovative behaviour. Leadership \& Organization Development Journal. 
Examining the link between Humble Leadership and Innovative Behaviour ...

Dr. Sameh Abd-ElMaksoud Aboul-Dahab

Anglin, A.H., Short, J.C., Drover, W., Stevenson, R.M., McKenny, A.F. and Allison, T.H., 2018. The power of positivity? The influence of positive psychological capital language on crowdfunding performance. Journal of Business Venturing, 33(4), pp.470-492.

Angus-Leppan, T., Metcalf, L. and Benn, S., 2010. Leadership styles and CSR practice: An examination of sensemaking, institutional drivers and CSR leadership. Journal of Business Ethics, 93(2), pp.189-213.

Bakker, A.B. and Albrecht, S., 2018. Work engagement: current trends. Career Development International.

Baskaran, K. and Rajarathinam, M., 2017. Influence of Psychological Capital on Innovative Behaviour among the Faculty Teaching in Online Environment. Asian Journal of Distance Education, 12(1), pp.60-68.

Bednall, T.C., E. Rafferty, A., Shipton, H., Sanders, K. and J. Jackson, C., 2018. Innovative behaviour: how much transformational leadership do you need?. British Journal of Management, 29(4), pp.796-816.

Bednall, T.C., E. Rafferty, A., Shipton, H., Sanders, K. and J. Jackson, C., 2018. Innovative behaviour: how much transformational leadership do you need?. British Journal of Management, 29(4), pp.796-816.

Birasnav, M. and Bienstock, J., 2019. Supply chain integration, advanced manufacturing technology, and strategic leadership: An empirical study. Computers \& Industrial Engineering, 130, pp.142-157.

Bockorny, K. and Youssef-Morgan, C.M., 2019. Entrepreneurs' courage, psychological capital, and life satisfaction. Frontiers in psychology, 10, p.789. 
Examining the link between Humble Leadership and Innovative Behaviour ...

Dr. Sameh Abd-ElMaksoud Aboul-Dahab

Bos-Nehles, A., Renkema, M. and Janssen, M., 2017. HRM and innovative work behaviour: A systematic literature review. Personnel review.

Bos-Nehles, A., Renkema, M. and Janssen, M., 2017. HRM and innovative work behaviour: A systematic literature review. Personnel review.

Bouzari, M. and Karatepe, O.M., 2017. Test of a mediation model of psychological capital among hotel salespeople. International Journal of Contemporary Hospitality Management.

Carmona-Halty, M., Salanova, M., Llorens, S. and Schaufeli, W.B., 2019. How psychological capital mediates between study-related positive emotions and academic performance. Journal of Happiness Studies, 20(2), pp.605-617.

Chen, Q., Kong, Y., Niu, J., Gao, W., Li, J. and Li, M., 2019. How leaders' psychological capital influence their followers' psychological capital: social exchange or emotional contagion. Frontiers in psychology, 10, p.1578.

Chung, Y.W. and Kim, T., 2017. Impact of using social network services on workplace ostracism, job satisfaction, and innovative behaviour. Behaviour \& Information Technology, 36(12), pp.1235-1243.

Cummings, G.G., Tate, K., Lee, S., Wong, C.A., Paananen, T., Micaroni, S.P. and Chatterjee, G.E., 2018. Leadership styles and outcome patterns for the nursing workforce and work environment: A systematic review. International journal of nursing studies, 85, pp.19-60.

Dulewicz, V. and Higgs, M., 2005. Assessing leadership styles and organisational context. Journal of managerial Psychology. 
Examining the link between Humble Leadership and Innovative Behaviour ...

Dr. Sameh Abd-ElMaksoud Aboul-Dahab

Eid, R. and Agag, G., 2020. Determinants of innovative behaviour in the hotel industry: a cross-cultural study. International Journal of Hospitality Management, 91, p.102642.

Engelbrecht, A.S., Heine, G. and Mahembe, B., 2017. Integrity, ethical leadership, trust and work engagement. Leadership \& Organization Development Journal.

Escribá-Carda, N., Balbastre-Benavent, F. and Canet-Giner, M.T., 2017. Employees' perceptions of high-performance work systems and innovative behaviour: The role of exploratory learning. European Management Journal, 35(2), pp.273-281.

Farid, H., Hakimian, F. and Ismail, M.N., 2017. How Malaysian managers persuade employees' innovative behaviour?. International Journal of Management and Enterprise Development, 16(4), pp.291-307.

Fiaz, M., Su, Q. and Saqib, A., 2017. Leadership styles and employees' motivation: Perspective from an emerging economy. The Journal of Developing Areas, 51(4), pp.143-156.

Fornell, C. and Larcker, D.F., 1981. Structural equation models with unobservable variables and measurement error: Algebra and statistics.

Gandolfi, F. and Stone, S., 2018. Leadership, leadership styles, and servant leadership. Journal of Management Research, 18(4), pp.261-269.

Gawke, J.C., Gorgievski, M.J. and Bakker, A.B., 2017. Employee intrapreneurship and work engagement: A latent change score approach. Journal of Vocational Behavior, 100, pp.88-100. 
Examining the link between Humble Leadership and Innovative Behaviour ...

Dr. Sameh Abd-ElMaksoud Aboul-Dahab

Ghosh, V., Bharadwaja, M., Yadav, S. and Kabra, G., 2019. Team-member exchange and innovative work behaviour: The role of psychological empowerment and creative self-efficacy. International Journal of Innovation Science.

Gross, R. and Cabanda, E., 2017. Predicting the relationship between leadership styles and entrepreneurial orientation and innovative behaviour in Indian immigrant firms. International Journal of Society Systems Science, 9(3), pp.222-241.

Gupta, M. and Shaheen, M., 2017. Impact of work engagement on turnover intention: moderation by psychological capital in India. Business: Theory and Practice, 18, pp.136-143.

Gupta, M., Shaheen, M. and Reddy, P.K., 2017. Impact of psychological capital on organizational citizenship behavior: Mediation by work engagement. Journal of Management Development.

Gupta, M., Shaheen, M. and Reddy, P.K., 2017. Impact of psychological capital on organizational citizenship behavior: Mediation by work engagement. Journal of Management Development.

Gutermann, D., Lehmann-Willenbrock, N., Boer, D., Born, M. and Voelpel, S.C., 2017. How leaders affect followers' work engagement and performance: Integrating leader- member exchange and crossover theory. British Journal of Management, 28(2), pp.299-314.

Huertas-Valdivia, I., Gallego-Burín, A.R. and Lloréns-Montes, F.J., 2019. Effects of different leadership styles on hospitality workers. Tourism management, 71, pp.402-420. 
Examining the link between Humble Leadership and Innovative Behaviour ...

Dr. Sameh Abd-ElMaksoud Aboul-Dahab

Hughes, M., Rigtering, J.C., Covin, J.G., Bouncken, R.B. and Kraus, S., 2018. Innovative behaviour, trust and perceived workplace performance. British Journal of Management, 29(4), pp.750-768.

Hussain, M. and Hassan, D., 2016. The leadership styles dilemma in the business world. International Journal of Organizational Leadership, 5, pp.411-425.

Jang, Y.J., Zheng, T. and Bosselman, R., 2017. Top managers' environmental values, leadership, and stakeholder engagement in promoting environmental sustainability in the restaurant industry. International Journal of Hospitality Management, 63, pp.101-111.

Jungbauer, K.L., Loewenbrück, K., Reichmann, H., Wendsche, J. and Wegge, J., 2018. How does leadership influence incident reporting intention in healthcare? A dual process model of leader-member exchange. German Journal of Human Resource Management, 32(1), pp.27-51.

Kang, H.J.A. and Busser, J.A., 2018. Impact of service climate and psychological capital on employee engagement: The role of organizational hierarchy. International Journal of Hospitality Management, 75, pp.1-9.

Katsaros, K.K., Tsirikas, A.N. and Kosta, G.C., 2020. The impact of leadership on firm financial performance: the mediating role of employees' readiness to change. Leadership \& Organization Development Journal.

Kuchinke, K.P., 1999. Leadership and culture: Work-related values and leadership styles among one company's US and German telecommunication employees. Human resource development quarterly, 10(2), pp.135-154. 
Examining the link between Humble Leadership and Innovative Behaviour ...

Dr. Sameh Abd-ElMaksoud Aboul-Dahab

Luthans, K.W., Luthans, B.C. and Chaffin, T.D., 2019. Refining grit in academic performance: The mediational role of psychological capital. Journal of Management Education, 43(1), pp.35-61.

Mäkikangas, A., 2018. Job crafting profiles and work engagement: A personcentered approach. Journal of Vocational Behavior, 106, pp.101-111.

Mao, Y., He, J., Morrison, A.M. and Andres Coca-Stefaniak, J., 2020. Effects of tourism CSR on employee psychological capital in the COVID-19 crisis: from the perspective of conservation of resources theory. Current Issues in Tourism, pp.1-19.

Mokhber, M., Khairuzzaman, W. and Vakilbashi, A., 2018. Leadership and innovation: The moderator role of organization support for innovative behaviors. Journal of Management \& Organization, 24(1), pp.108-128.

Mölders, S., Brosi, P., Bekk, M., Spörrle, M. and Welpe, I.M., 2018. Support for quotas for women in leadership: The influence of gender stereotypes. Human Resource Management, 57(4), pp.869-882.

Montani, F., Dagenais-Desmarais, V., Giorgi, G. and Grégoire, S., 2018. A conservation of resources perspective on negative affect and innovative work behaviour: The role of affect activation and mindfulness. Journal of Business and Psychology, 33(1), pp.123-139.

Montani, F., Dagenais-Desmarais, V., Giorgi, G. and Grégoire, S., 2018. A conservation of resources perspective on negative affect and innovative work behaviour: The role of affect activation and mindfulness. Journal of Business and Psychology, 33(1), pp.123-139. 
Examining the link between Humble Leadership and Innovative Behaviour ...

Dr. Sameh Abd-ElMaksoud Aboul-Dahab

Mughal, M., Bahaudin, A. and Salleh, N., 2019. Behavioral factors for IT project success in Pakistan: Moderating effect of leadership styles. Management Science Letters, 9(7), pp.987-996.

Muhammed, S. and Zaim, H., 2020. Peer knowledge sharing and organizational performance: the role of leadership support and knowledge management success. Journal of Knowledge Management.

Mutonyi, B.R., Slåtten, T. and Lien, G., 2020. Empowering leadership, work group cohesiveness, individual learning orientation and individual innovative behaviour in the public sector: empirical evidence from Norway. International Journal of Public Leadership.

Ortega-Maldonado, A. and Salanova, M., 2018. Psychological capital and performance among undergraduate students: the role of meaning-focused coping and satisfaction. Teaching in Higher Education, 23(3), pp.390-402.

Orth, M. and Volmer, J., 2017. Daily within-person effects of job autonomy and work engagement on innovative behaviour: The cross-level moderating role of creative self-efficacy. European Journal of Work and Organizational Psychology, 26(4), pp.601-612.

Orth, M. and Volmer, J., 2017. Daily within-person effects of job autonomy and work engagement on innovative behaviour: The cross-level moderating role of creative self-efficacy. European Journal of Work and Organizational Psychology, 26(4), pp.601-612.

Pashiardis, P. and Brauckmann, S., 2011. A validation study of the leadership styles of a holistic leadership theoretical framework. International Journal of Educational Management. 
Examining the link between Humble Leadership and Innovative Behaviour ...

Dr. Sameh Abd-ElMaksoud Aboul-Dahab

Preacher, K.J., Rucker, D.D. and Hayes, A.F., 2007. Addressing moderated mediation hypotheses: Theory, methods, and prescriptions. Multivariate behavioral research, 42(1), pp.185-227.

Rahbi, D.A., Khalid, K. and Khan, M., 2017. The effects of leadership styles on team motivation. Academy of Strategic Management Journal, 16(3).

Saeed, T., Almas, S., Anis-ul-Haq, M. and Niazi, G.S.K., 2014. Leadership styles: relationship with conflict management styles. International Journal of Conflict Management.

Saha, R., Cerchione, R., Singh, R. and Dahiya, R., 2020. Effect of ethical leadership and corporate social responsibility on firm performance: A systematic review. Corporate Social Responsibility and Environmental Management, 27(2), pp.409-429.

Schaufeli, W.B., Shimazu, A., Hakanen, J., Salanova, M. and De Witte, H., 2019. An ultra-short measure for work engagement: the UWES-3 validation across five countries. European Journal of Psychological Assessment, 35(4), p.577.

Sethuraman, K. and Suresh, J., 2014. Effective leadership styles. International Business Research, 7(9), p.165.

Sharma, N., 2017. Innovative Behaviour Of Indian Micro Small And Medium Enterprises: An Empirical Study. International Journal of Innovation Management, 21(07), p.1750061.

Shrout, P.E. and Bolger, N., 2002. Mediation in experimental and nonexperimental studies: new procedures and recommendations. Psychological methods, 7(4), p.422. 
Examining the link between Humble Leadership and Innovative Behaviour ...

Dr. Sameh Abd-ElMaksoud Aboul-Dahab

Su, Z.X., Wang, Z. and Chen, S., 2020. The impact of CEO transformational leadership on organizational voluntary turnover and employee innovative behaviour: the mediating role of collaborative HRM. Asia Pacific Journal of Human Resources, 58(2), pp.197-219.

Tavakol, M. and Dennick, R., 2011. Making sense of Cronbach's alpha. International journal of medical education, 2, p.53.

Teoman, S. and Ulengin, F., 2018. The impact of management leadership on quality performance throughout a supply chain: an empirical study. Total Quality Management \& Business Excellence, 29(11-12), pp.1427-1451.

Tsai, S.P., 2018. Innovative behaviour of knowledge workers and social exchange attributes of financial incentive: implications for knowledge management. Journal of knowledge management.

Tsaur, S.H., Hsu, F.S. and Lin, H., 2019. Workplace fun and work engagement in tourism and hospitality: The role of psychological capital. International Journal of Hospitality Management, 81, pp.131-140.

Van Engen, M.L. and Willemsen, T.M., 2004. Sex and leadership styles: A meta-analysis of research published in the 1990s. Psychological reports, 94(1), pp.3-18.

Van Wart, M., Roman, A., Wang, X. and Liu, C., 2017. Integrating ICT adoption issues into (e-) leadership theory. Telematics and Informatics, 34(5), pp.527-537.

Vinkenburg, C.J., Van Engen, M.L., Eagly, A.H. and Johannesen-Schmidt, M.C., 2011. An exploration of stereotypical beliefs about leadership styles: Is transformational leadership a route to women's promotion?. The Leadership Quarterly, 22(1), pp.10-21. 
Examining the link between Humble Leadership and Innovative Behaviour ...

Dr. Sameh Abd-ElMaksoud Aboul-Dahab

Wang, S., Yu, M., Jiang, J., Zhang, W., Guo, X., Chang, S., Wang, Z., Klinger, T., Tesauro, G. and Campbell, M., 2017. Evidence aggregation for answer reranking in open-domain question answering.arXiv preprint arXiv:1711.05116.

Wang, Y., Liu, J. and Zhu, Y., 2018. How does humble leadership promote follower creativity? The roles of psychological capital and growth need strength. Leadership \& Organization Development Journal.

Will, M.G., Kfairy, M. and Mellor, R., 2017. Innovative behaviour, organizational structures and corporate performance. In Academy of Management Proceedings (Vol. 2017, No. 1, p. 11303). Briarcliff Manor, NY 10510: Academy of Management.

Xu, J., Liu, Y. and Chung, B., 2017. Leader psychological capital and employee work engagement. Leadership \& Organization Development Journal.

Xu, J., Liu, Y. and Chung, B., 2017. Leader psychological capital and employee work engagement. Leadership \& Organization Development Journal.

Zopiatis, A. and Constanti, P., 2010. Leadership styles and burnout: is there an association?. International Journal of Contemporary Hospitality Management. 